\title{
The use of tumour necrosis factor alpha-blockers in daily routine. An Austrian consensus project
}

\author{
Burkhard F. Leeb • Elke Böttcher • Hans-Peter Brezinschek • Christoph Czerwenka • \\ Manfred Herold • Hans Hitzelhammer • Franz Mayrhofer • Rudolf Puchner • \\ Franz Rainer • Bernhard Rintelen • Michael Schirmer • Ulrike Stuby • Hans Bröll
}

Received: 29 August 2008 /Revised: 20 September 2009 / Accepted: 6 October 2009/Published online: 11 November 2009

(C) The Author(s) 2009. This article is published with open access at Springerlink.com

\begin{abstract}
To define relevant disease parameters and their respective limits indicating the initiation of TNF- $\alpha$ blockers in individual patients. Subsequently, to analyze retrospectively patients with rheumatoid arthritis (RA), psoriatic arthritis (PsA) or ankylosing spondylitis (AS), who started TNF- $\alpha$ inhibition in 2006. Points to consider, regarded relevant for individual treatment decisions as well as their assessment methods, were ascertained by experts' consensus applying the Delphi technique. Subse-
\end{abstract}

B. F. Leeb $(\bowtie) \cdot$ B. Rintelen

Karl Landsteiner-Institute for Clinical Rheumatology,

First and Second Department of Medicine,

Center for Rheumatology, Lower Austria,

State Hospital Stockerau,

Landstrasse 18,

Stockerau 2000, Austria

e-mail: burkhard.leeb@stockerau.lknoe.at

E. Böttcher $\cdot$ H. Bröll

Rheumazentrum Oberlaa,

Cluster for Rheumatology, Ludwig Boltzmann Institute,

Vienna, Austria

H.-P. Brezinschek

Rheumatology, Medical University Graz,

Graz, Austria

C. Czerwenka

Private Office, Specialisation on Rheumatology, Rheumatology, EMCO-Klinik,

Salzburg, Austria

M. Herold

Rheumatology, Medical University Innsbruck, Innsbruck, Austria

H. Hitzelhammer

Ambulatorium Strohgasse, Wiener Gebietskrankenkasse,

Vienna, Austria quently, these parameters' thresholds with respect to the initiation of a TNF- $\alpha$-blocker were identified. Thereafter, the rheumatologists representing 12 centres all over Austria agreed to retrospectively analyze their patients started on a TNF- $\alpha$-blocker in 2006. Experts' opinion regarding disease parameters relevant to initiate TNF- $\alpha$ blockers in RA patients only slightly differed from those applied in clinical trials, but the parameters' threshold values were considerably lower. For PsA patients, some

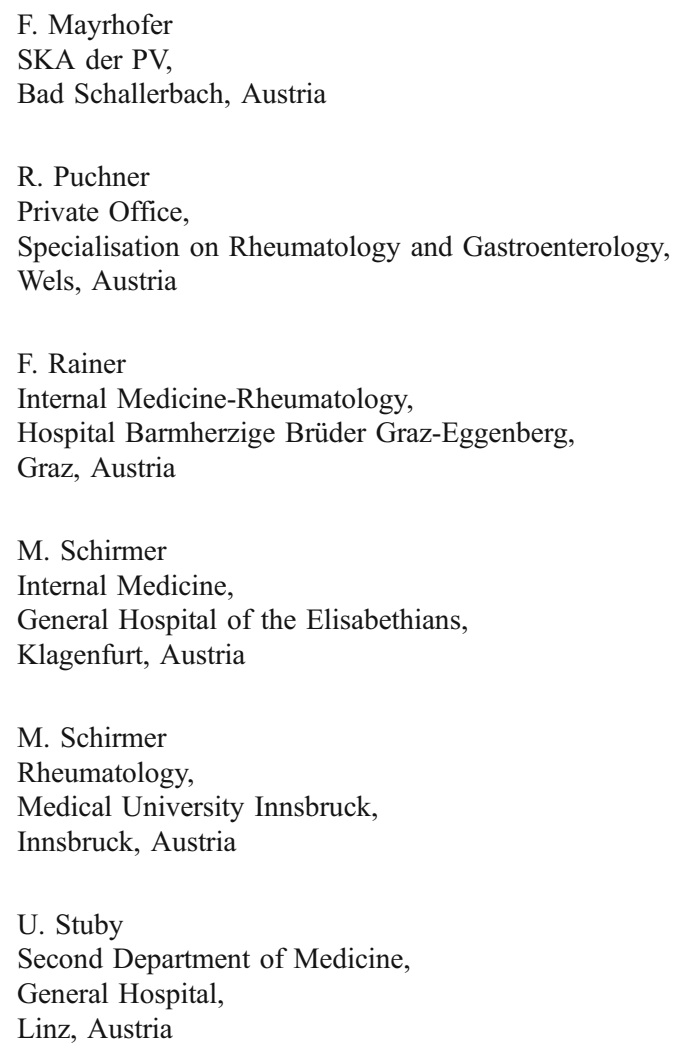


differences and for AS patients, considerable differences between experts' opinion and clinical studies appeared, which held also true for decisive parameters' means and thresholds. Six hundred and fifty patients, started on TNFblockers in 2006, could be analyzed retrospectively, 408 RA patients (53.3 years mean, 340 females), 93 PsA patients (48.9 years mean, 59 males) and 149 AS patients AS (42.2 years mean, 108 males), representing approximately $25 \%$ of all Austrian patients initiated on a TNFblocker in this respective year. Far more individualized, patient-oriented treatment approaches, at least in part, are applied in daily routine compared with those derived from clinical trials or recommendations from investigative rheumatologists.

Keywords Initiation $\cdot$ Patient characteristics $\cdot$ TNF-blockers

$\begin{array}{ll}\text { Abbrevations } \\ \text { SJC } & \text { Swollen joint count } \\ \text { TJC } & \text { Tender joint count } \\ \text { DAS28 } & \text { Disease activity score } 28 \\ \text { CRP } & \text { C-reactive protein } \\ \text { ESR } & \text { Erythrocyte sedimentation rate } \\ \text { RF } & \text { Rheumatoid factor } \\ \text { NSAID } & \text { Non-steroidal anti-inflammatory drug } \\ \text { DMARD } & \text { Disease-modifying anti-rheumatic drug } \\ \text { BASDAI } & \text { Bath ankylosing spondylitis disease activity } \\ & \text { index } \\ \text { CI } & \text { Confidence interval }\end{array}$

\section{Introduction}

In chronic inflammatory joint diseases tumour necrosis factor-alpha (TNF- $\alpha$ ) plays a pivotal role in initiating and maintaining processes which ultimately lead to cartilage damage, and bone destruction [1]. Therefore, interfering with the activity of this cardinal cytokine leads to significant clinical improvement and to a reduction of damage respectively [2], which has been shown in numerous controlled clinical trials. The administration of the TNF- $\alpha$ inhibitors Etanercept (ETA), Infliximab (IFX) and Adalimumab (ADA) significantly reduces symptoms and radiological evident damage as well as improves function and quality of life in patients with rheumatoid arthritis (RA), psoriatic arthritis (PsA) and ankylosing spondylitis (AS) [3-11]. In PsA patients, ETA, IFX and ADA have been shown to control rash, improve symptoms, function and quality of life, as well as to retard radiological evident progression [6-8, 12, 13].

Several international recommendations dealing with the indication for initiating TNF-inhibitors in patients with rheumatic diseases have been published [14, 15]. According to an international consensus, TNF- $\alpha$ inhibitors are recommended for the treatment of severe and active rheumatoid arthritis after the failure of two diseasemodifying anti-rheumatic drugs (DMARDs) in an adequate dosage for an adequate duration - unless not tolerated or contraindicated [14]. For the treatment of ankylosing spondylitis, the joint assessment in ankylosing spondylitis (ASAS) and EULAR recommendations consider a patient with a diagnosis of definite AS to be a candidate for initiating TNF inhibitors, if at least two non-steroidal antiinflammatory drugs (NSAIDs) have previously failed, the patient has a BASDAI (Bath Ankylosing Spondylitis Disease Activity Index score) of $\geq 4$, and if a positive expert's opinion based on clinical features is present [15].

However, those recommendations have never been attempted to be validated in daily routine, whether they really contribute to improved patient care. Expert recommendations, of course, could remarkably improve daily rheumatology care; though, if they are not disseminated, discussed and widely accepted, they remain l'art pour l'art.

Since recommendations for the use of TNF- $\alpha$-blockers in rheumatic disorders are primarily based on the one hand on inclusion and exclusion criteria of clinical trials and on the other on their respective results, they can be regarded valid, if even, only on the group level. In daily routine, though, we rarely see that highly active patients usually included into such studies. Therefore, the question arises to which extent such recommendations can be transferred to daily routine, particularly the individual patient's situation.

Based on this background, it was the aim of this study, using a Delphi technique among a group of practising clinical rheumatologists, to decide and quantify parameters, relevant for treatment decisions in individual patients, with respect to the initiation of TNF- $\alpha$-blocker therapy in RA, PsA and AS first. After having done so, the group agreed to evaluate routine patients with RA, PsA or AS who commenced TNF-blocking therapy in 2006 in order to attempt a validation of the parameters and the respective thresholds which the group has agreed upon before.

Here, we report the results of this process, which approached the problem of indicating TNF-blocker therapy from the situation given in daily routine.

\section{Methods}

The working group comprised 13 rheumatologists, representing 11 rheumatology centres all over Austria, invited by the convenors (BFL, MH and $\mathrm{HB}$ ). As a prerequisite, all the members of the working group had to be involved in routine patient care. As the first step, the working group agreed to focus on RA, PsA and AS to define respective 
patient profiles for the initiation of TNF- $\alpha$-blockers and to employ a Delphi technique to achieve consensus. All disease-related conditions considered important by each group member with respect to a therapeutic decision in an individual RA, PsA or AS patient were gathered first, regardless whether these were objective, semi-objective or patient-driven findings.

For RA the number of conditions primarily nominated totalled to 34 , including parameters as profession, patient's compliance, co-morbidities, amount of corticosteroids necessary/day, and frequency of flares besides the classical disease activity parameters known from clinical trials. For AS, 28 parameters were nominated, amongst them duration of inflammatory back pain, number of days with inflammatory back pain, enthesitis, social situation and peripheral arthritis. For PsA, at last 29 candidate findings could be identified, amongst them life-style, profession, involvement of little finger joints, compliance and dactylitis.

At this stage of the process, the group agreed that at least four parameters meaningful for initiating TNF-blockers had to be defined by consensus for either RA, AS and PsA. A parameter would be finally accepted, if it had achieved an acceptance of $60 \%$ by the panel, whereas a parameter, not or only nominated once during the following Delphi rounds, was to be withdrawn. Whenever four parameters would have achieved acceptance, the Delphi procedure was to be terminated. Subsequently, after having achieved consensus with respect to the single parameters, their respective method of assessment was determined applying the same Delphi technique. As the final step of the process' first part, the parameters' lower threshold values referring to the initiation of TNF-blocking therapy had to be identified. To this end a consensus meeting was organized with an attendance rate of $85 \%$. The threshold values for each single parameter were worked out by voting and calculating the lower 95\% CI for the experts' opinion's mean.

At the end of the consensus meeting, the panellists agreed upon a retrospective analysis of all their patients started on a TNF- $\alpha$-blocker in 2006 . The rationale was to find out whether the parameters revealed by a theoretical procedure could be regarded valid with respect to their documentation rate and relevance in daily routine. In addition, the parameters elaborated by the Delphi-process should be compared with large clinical trials inclusion criteria in order to get a picture about the differences between the clinical trial world and daily routine. Above all, this analysis should answer the question whether a situation considered desirable, as expressed by the elaborated key parameters and their threshold values, would remain preferable after having obtained knowledge about the real situation.

\section{Results}

Three Delphi rounds were necessary to finally identify eight points-to-consider for the initiation of TNF-blockers in RA patients, six ones for PsA and four ones for AS patients, respectively, see Table 1. It took another two Delphi rounds to elaborate the respective assessment methods, see also Table 1. The mean participation in the five Delphi rounds amounted to about $80 \%$.

Regarding the initiation of TNF- $\alpha$-blockers in RA patients, the highest degree of congruence between the experts' opinion and the literature evidence as indicated by the inclusion criteria of large clinical trials or by international recommendations could be found. Interestingly, patient's global assessment, although necessary to calculate most of the disease activity scores [16-18] constituted no explicit inclusion criterion in any large clinical trial. With respect to joint counts, there was strong agreement that a total joint count is essential for clinical judgement before any therapeutic change in an individual patient, however, that a 28 joint count could be regarded sufficient for routine monitoring [16]. Radiological progression was primarily nominated as a key point for RA patients, however, later on defining thresholds, the participants achieved consensus, that positive evidence for radiological progression would not be mandatory to consider TNF-blocker therapy. Subsequently, the documentation rate of radiological progression was found considerably low during the retrospective patient evaluation.

Much more discrepancies occurred with respect to the management of PsA and AS patients, see also Table 1. For PsA, enthesitis, dactylitis and spine involvement were regarded that crucial to be explicitly nominated as key parameters. In contrast to several clinical trials, failure to previous NSAID treatment was regarded of less importance by the panellists, as well as a positive finding for RF [6-8, 12]. Of course the skin disease's extent constitutes a major issue for a therapeutic decision in an individual PsA patient. Although psoriatic skin disease of course constitutes a dermatological outcome and may warrant anti-TNF therapy per se, no physician would stop this kind of therapy, if the patient's skin cleared up but there was no benefit on the joints, and subsequently the patient would then be considered a rheumatological "treatment failure".

Regarding AS only, the BASDAI was found to be part of both, namely the inclusion criteria of clinical trials and the parameter set developed by the group. With the exception of one study [19], NSAID failure and peripheral arthritis were no major issues of large clinical trials.

After having agreed upon the key parameters the elaboration of their respective threshold values constituted the next step of the process. Those were determined during another two Delphi rounds (methods of assessment) and the 
Table 1 Experts' points to consider and assessment methods for initiating TNF inhibitors in RA, PsA and AS patients

\begin{tabular}{ll}
\hline Rheumatoid arthritis & \\
Parameter & Method of assessment \\
SJC & Total joint count \\
TJC & Total joint count \\
VAS patient global assessment & $0-100 \mathrm{~mm}$ \\
DAS & DAS28 \\
CRP & mg/l; mg/dl \\
ESR & mm/1st hour \\
DMARDs & Failure number+preparation \\
X-ray progression & Yes/no; physician's assessment \\
Psoriatic arthritis & \\
Parameter & Method of assessment \\
SJC & Total joint count + dactylitis + enthesitis \\
TJC & Total joint count + dactylitis + enthesitis \\
Degree of skin involvement & Likert $0-10$, physical assessment \\
Spine involvement & Yes/no; physical assessment \\
DMARDs failure & Number+preparation \\
X-ray progression & Yes/no; physician's assessment \\
Ankylosing spondylitis & \\
Parameter & Method of assessment \\
BASDAI & $0-10$ \\
Failure, response to NSAIDs & Number \\
Positive radiological findings incl. MRI & Yes/no; physician's assessment \\
Presence and extent of peripheral arthritis & SJC+TJC+dactylitis + enthesitis \\
\hline
\end{tabular}

consensus meeting (threshold values). These limits, surprisingly enough, were found to be considerably lower than the respective ones when those parameters were applied as inclusion criteria in large clinical trials with TNF-blockers. The respective values are given in Tables 2, 3 and 4 .

Retrospective analysis of patients

At the consensus meeting the group members agreed to retrospectively analyse their patients, initiated on a TNFblocker in 2006 for the first time, in order to answer the question whether the group's consensus was in line with real life in daily routine. Although the panellist were well aware of the problems implicated with a retrospective evaluation, this decision was taken in order speed up the project.

Overall, in the participating centres 650 patients were started on TNF-inhibiting therapy in 2006. Four hundred and eight patients with RA (mean age 53.3 years, 340 females), 93 patients with PsA (mean age 48.9 years, 59 males) and 149 patients with AS (mean age 42.2 years, 108 males). This number of patients represents approximately $25 \%$ of all Austrian patients initiated on a TNFblocker for the first time in this respective year. Given the number of patients, the different surroundings and professional settings the panellist are working, these

Table 2 Parameters, experts' mean values and RA patients' $(n=408)$ mean values

\begin{tabular}{|c|c|c|c|c|c|}
\hline Parameter RA & Experts'mean & Lower $95 \% \mathrm{CI}$ & Patients'mean & Range & Percentdocumentation \\
\hline SJC & 1 & 1 & 7.03 & $0-32$ & 86.3 \\
\hline TJC & 4 & 2 & 9.64 & $0-49$ & 85.3 \\
\hline VAS patient's global ass. & 43 & 35 & 47.61 & $0-100$ & 87.0 \\
\hline CRP (0.5 normal) & 0.5 & 0.5 & 1.85 & $0-13.2$ & 58.8 \\
\hline ESR & 15 & 11 & 35.41 & $2-113$ & 91.2 \\
\hline DMARDs failure $(n)$ & 2 & 1 & 2.47 & $0-8$ & 93.1 \\
\hline DAS28 (calculated) & & 3.24 & 5.02 & $0.77-8.09$ & 56.1 \\
\hline X-ray & No & No & $57.8 \%$ yes & No-yes & 38.7 \\
\hline
\end{tabular}


Table 3 Parameters, experts' mean values and PsA patients' $(n=93)$ mean values

\begin{tabular}{lccccc}
\hline Parameter PsA & Experts'mean & Lower 95\% CI & Patients'mean & Range & Percentdocumentation \\
\hline SJC+dactylitis+enthesitis & 1 & 1 & 5.1 & $0-22$ & 68.8 \\
TJC+dactylitis + enthesitis & 3 & 2 & 8.6 & $0-36$ & 72.0 \\
skin involvement (VAS 0-10) & 0.3 & 0 & 4 & $0-10$ & 49.5 \\
DMARDs failure ( $n$ ) & 1 & 1 & $51.0 \%$ yes & No-yes & 48.4 \\
X-ray progression & No & No & No & $29.6 \%$ yes & No-yes \\
Spine involvement & No & & & 60.2 \\
\hline
\end{tabular}

patients may be regarded representative for all Austrian patients, although no information with respect to the remaining $75 \%$ of Austrian anti-TNF-treated patients was obtained.

Tables 2, 3 and 4 also summarize the mean values and the respective range for the key parameters, identified in the patients retrospectively. In addition, their documentation rate was also ascertained retrospectively and is given in the respective tables.

The documentation rate for the single parameter's documentation differed consistently between the three diseases. For RA, a $79.7 \%$ documentation rate could be found retrospectively, while it amounted to $64.1 \%$ for AS and to $55.2 \%$ for PsA, respectively.

According to the results of this evaluation, the patient population in general can be regarded severely diseased $[16,20]$, however, the respective ranges indicate high individual variability with respect to disease activity. As it can be seen in the tables $18.5 \%$ of the RA patients, $23.6 \%$ of the PsA patients and $26.3 \%$ of the AS patients, did not even meet the lower limits elaborated by the panel at the time point TNF-blocking therapy was initiated.

\section{Discussion}

Practising rheumatologists from all over Austria participated in this project with the main purpose to figure out their strategies with respect to the initiation of TNF-blocking therapy in single RA, PsA and AS patients. Hence, the key question at the beginning of the Delphi procedure was: "What do I regard essential for the decision to initiate a TNF-blocker in a single patient?"
TNF-blocking agents have proven their efficacy as well as their tolerability in numerous groups of patients during clinical trials [3-11]. However, the results of such trials may only be partially transferable into daily individual patient care. In clinical routine, not so many patients are as highly active as those usually included into clinical trials and additionally, those trial patients somewhat constitute a distinct group - not easily comparable to clinical routine regarding e.g. concomitant diseases and medication-given the restrictive inclusion criteria of clinical trials [4, 21, 22]. A lot of publications are dealing with this situation [23-25]. Thus, this group of practising rheumatologists attempted at least in part to answer the question which kind of patients should be treated with TNF-blockers by experts' consensus based on their personal experience, on the literature evidence as well as on their estimation of patients' perceptions [26]. In Austria, anti-TNF therapy is fully reimbursed after prescription of a rheumatologist by the social insurances, if at least one conventional DMARD has failed; nominal values of any disease activity score of course are recommended to support the treatment decision, but they are not obligatory.

As the primary result of this consensus project-not unexpected - considerable differences between daily rheumatologic practise and the world of investigative rheumatology occurred, as most of the recommendations for the initiation of anti-TNF therapy-including the Austrian ones-are deducted from clinical trials $[14,15,27]$.

In particular, the great number of parameters quoted at the beginning of the Delphi process witnesses how differently rheumatologists approach the assessment of individual patients in contrast to the necessary uniform regulations of clinical trials. As expected, the highest

Table 4 Parameters, experts' mean values and AS patients' $(n=149)$ mean values

\begin{tabular}{lllllr}
\hline Parameter AS & Experts'mean & Lower 95\% CI & Patients'mean & Range & Percentdocumentation \\
\hline BASDAI & 3.6 & 3.4 & 5.98 & $2.63-9.61$ & 66.7 \\
NSAID failure $(n)$ & 2 & 2 & 2.26 & $1-5$ & 76.7 \\
Peripheral arthritis & 1 & 1 & 1.63 & $0-16$ & 52.7 \\
Positive imaging, incl. MRI & Yes & Yes & $90 \%$ yes & Yes-no & 60.0 \\
\hline
\end{tabular}


degree of analogy to clinical trials was found for RA, the lowest for PsA. Of course the great experience with RA clinical trials 1994 exerted a great influence on the rheumatologic community in this respect $[3,28]$. The issue of radiological progression can be regarded an example for the influence clinical trials may exert. Although primarily chosen as a key point, there was later consensus that even if no progression occurs TNF-blockers may be indicated, suggesting that radiological progression may be of scientific, however, of lower practical worthiness [29, 30].

Publications on PsA and AS appeared particularly later and less frequent $[9,13]$. Therefore, they apparently did not affect the rheumatologists' thoughts and attitudes that extensively.

It is of particular interest that no formal evaluation of functionality and quality of life by a questionnaire was regarded that important to be included into the key parameters' list. [31, 32] With respect to disease activity assessment, it seems to be that rheumatologists are focused on joints rather than on functional status and pain as important measures of disease activity. Concordantly, we could find a reasonably high documentation rate for joint counts, which is somewhat different to published data from other countries [33]. In daily routine, there is always a battle between the need of documentation and the respective time requirements. Thus, the refrain from HAQ scores or SF-36 may be explained by the time needed for their evaluation. Considering all the parameters chosen by the clinicians, a focus on time-sparing procedures nevertheless providing reasonable reliability can be recognized.

Short fully patient administered questionnaires, such as the Routine Assessment of Patient Index Data 3 or a modified version of the Rheumatoid Arthritis Disease Activity Index (RADAI-5) could provide a solution for the problem of documentation and the time necessary for it [34, 35].

Striking differences between clinical trials and subsequent international recommendations elaborated by investigative rheumatologists on the one hand and the practising rheumatologists' opinion on the other, however, were found with respect to the disease activity thresholds for the initiation of TNF-blockers [4-15, 27].

In RA clinical trials, the inclusion values for SJC, TJC and ESR were particularly higher than our experts' mean thresholds, which can be regarded in line with recent publications [23-25].

In patients with PsA or AS, discrepancies not only regarding the numerical limits, but regarding the decisive parameters themselves occurred. Inclusion criteria and scores applied in clinical trials differ considerably [6-8, 36]. Most of the studies included only patients at a rather high disease activity and severity [6-8]. In studies with AS patients, conducted before the publication of the ASAS recommendations for the initiation of TNF-inhibitor therapy (i.e. BASDAI $\geq 4$ and the failure of at least two NSAIDs) the failure for at least two NSAIDs did not constitute an inclusion criterion [9-11, 14].

The rate for the single parameter's documentation differed consistently between the three diseases. For RA patients a $79.7 \%$ documentation rate could be found retrospectively, which can be regarded high enough to justify some conclusions. For AS patients the documentation rate amounted to $64.1 \%$ and to $55.2 \%$ for PsA, respectively, which may limit the validity of respective deductions.

In this evaluation of roughly $25 \%$ of the Austrian TNFblocker patients, initiated in 2006, a great number of patients appeared to be far below the usual thresholds for disease activity applied in clinical trials. Retrospective analyses are of course fraught with problems and the results obtained have to be regarded in this context. The impossibility to ultimately clarify causalities constitutes one main issue in this respect as well as a recall bias one another. Therefore this retrospective research was not intended to prove but to give empirical evidence to strengthen the primary hypothesis that patients in clinical routine are substantially different from those in clinical trials.

The low thresholds for the decisive parameters elaborated by expert's consensus were somewhat surprising and unexpected primarily. However, as worked out by the retrospective evaluation of patients, they mirror daily clinical routine, which has to deal with the individual patient's situation. In a very recently published French paper also $18 \%$ of patients with $\mathrm{SpA}$ did not fulfil the national recommendations at the onset of therapy, a result which can be seen in line with our results [37].

It turned out that in routine care even patients falling short of these already low limits, are initiated on TNFblocking therapy, e.g. with the intention to spare corticosteroids. Another major motivation for these prescribing off-license may be that TNF-blockers are regarded the last therapeutic choice in a patient with long-standing refractory disease and multiple treatment failures. In any case, the individual patient's situation, which is, as a kind of loophole, almost always included into recommendations, plays a great, if not the greatest role in daily routine.

Having said that, the results of the retrospective analysis also indicate the participating experts' persuasion that TNFblockers may also work in patients at lower disease activity [38]. Overall, the primary goal for the practising rheumatologist is improvement of the single patient's situation at his desk. In this respect patients' and physicians' perceptions of disease activity changes have been found substantially divergent [39]. Patient dependent features, such as age, profession, social circumstances, high doses of corticosteroids necessary to maintain low disease activity, intolerance of several treatments, severe impairment by an oligoarticular disease, cannot be part of clinical studies obviously. However, they constitute major issues in daily 
routine highly influencing daily therapeutic decisions, including the initiation of TNF-blockers.

Thus, for a lot of patient-related reasons, TNF-blockers are administered in patients at a disease activity stage; those compounds were not studied for. A thorough evaluation of these patients' disease courses, not complying with the therapeutic recommendations, deems mandatory to prove the physicians' intentions in those cases [38].

At the beginning of this project, it was hypothesized that far more individualized, patient-oriented treatment approaches are applied in daily routine than in clinical trials. The results obtained underlined this hypothesis. The question whether such individual approaches may contribute to an improvement of our treatment results and subsequently of our patients' situation can rather be answered by observational studies, than by the means of randomized clinical trials. There was consensus in the working group that practising rheumatologists should demand research goals they regard necessary to support and ease their daily work [40]. Additionally, the panellist agreed that simple and as uniform as possible, documentation of patients will finally result in improved patient care.

Disclosures This initiative was supported by an unrestricted grant of Wyeth-Lederle, Austria. The authors declare no conflict of interest. BF Leeb is the president of the Austrian Society for Rheumatology and Rehabilitation. M Herold is the president elect of the Austrian Society for Rheumatology and Rehabilitation. M Schirmer is the scientific secretary of the Austrian Society for Rheumatology and Rehabilitation.

Open Access This article is distributed under the terms of the Creative Commons Attribution Noncommercial License which permits any noncommercial use, distribution, and reproduction in any medium, provided the original author(s) and source are credited.

\section{References}

1. Feldman M, Taylor P, Paleolog E, Brennan FM, Maini RN (1998) Anti-TNF alpha therapy is useful in rheumatoid arthritis and Crohn's disease: analysis of the mechanism of action predicts utility in other diseases. Transplant Proc 30(8):4126-4127 Review

2. Feldmann M, Brennan FM, Foxwell BM, Taylor PC, Williams RO, Maini RN (2005) Anti-TNF therapy: where have we got to in 2005? J Autoimmun 25(Suppl):26-28 Epub 2005

3. Bathon JM, Martin RW, Fleischmann RM, Tesser JR, Schiff MH, Keystone EC et al (2000) A comparison of etanercept and methotrexate in patients with early rheumatoid arthritis. N Engl J Med 343(22):1586-1593

4. Breedveld FC, Weisman MH, Kavanaugh AF, Cohen SB, Pavelka $\mathrm{K}$, van Vollenhoven $\mathrm{R}$ et al (2006) The PREMIER study: a multicenter, randomized, double-blind clinical trial of combination therapy with adalimumab plus methotrexate versus methotrexate alone or adalimumab alone in patients with early, aggressive rheumatoid arthritis who had not had previous methotrexate treatment. Arthritis Rheum 54(1):26-37

5. Lipsky PE, van der Heijde DM, St Clair EW, Furst DE, Breedveld FC, Kalden JR, Smolen JS et al (2000) Anti-tumor necrosis factor trial in rheumatoid arthritis with concomitant therapy study group. Infliximab and methotrexate in the treatment of rheumatoid arthritis. Anti-tumor necrosis factor trial in rheumatoid arthritis with concomitant therapy study group. N Engl J Med 343(22):1594-1602

6. Antoni C, Krueger GG, de Vlam K, Birbara C, Beutler A, Guzzo C, IMPACT 2 Trial Investigators et al (2005) Infliximab improves signs and symptoms of psoriatic arthritis: results of the IMPACT 2 trial. Ann Rheum Dis 64:1150-1157

7. Mease PJ, Goffe BS, Metz J, Vanderstoep A, Finck B, Burge DJ (2000) Etanercept in the treatment of psoriatic arthritis and psoriasis: a randomised trial. Lancet 356:385-390

8. Mease PJ, Gladman DD, Ritchlin CT, Ruderman EM, Steinfeld SD, Choy EH et al (2005) Adalimumab Effectiveness in Psoriatic Arthritis Trial Study Group. Adalimumab for the treatment of patients with moderately to severely active psoriatic arthritis: results of a double-blind, randomized, placebo-controlled trial. Arthritis Rheum 52(10):3279-3289

9. Brandt J, Khariouzov A, Listing J, Haibel H, Sorensen H, Grassnickel L et al (2003) Six-month results of a double-blind, placebo-controlled trial of etanercept treatment in patients with active ankylosing spondylitis. Arthritis Rheum 48:1667-1675

10. Braun J, Brandt J, Listing J, Zink A, Alten R, Golder W et al (2002) Treatment of active ankylosing spondylitis with infliximab: a randomised controlled multicentre trial. Lancet 359:1187-1193

11. Haibel H, Rudwaleit M, Brandt HC, Grozdanovic Z, Listing J (2006) Kupper et al. Adalimumab reduces spinal symptoms in active ankylosing spondylitis: clinical and magnetic resonance imaging results of a fifty-two-week open-label trial. Arthritis Rheum 54(2):678-681

12. Kavanaugh A, Antoni CE, Gladman D, Wassenberg S, Zhou B, Beutler A, Keenan G et al (2006) The Infliximab Multinational Psoriatic Arthritis Controlled Trial (IMPACT): results of radiographic analyses after 1 year. Ann Rheum Dis 65(8):1038-1043

13. Mease PJ, Kivitz AJ, Burch FX, Siegel EL, Cohen SB, Ory P et al (2004) Etanercept treatment of psoriatic arthritis: safety, efficacy, and effect on disease progression. Arthritis Rheum 50(7):2264-2272

14. Furst DE, Breedveld FC, Kalden JR, Smolen JS, Burmester GR, Emery P, Keystone EC, Schiff MH, van Riel PL, Weinblatt ME, Weisman MH (2006) Updated consensus statement on biological agents for the treatment of rheumatic diseases, 2006. Ann Rheum Dis 65(Suppl 3):iii2-iii15

15. Zochling J, van der Heijde D, Burgos-Vargas R, Collantes E, Davis JC Jr, Dijkmans B et al (2006) ASAS/EULAR recommendations for the management of ankylosing spondylitis. Ann Rheum Dis 65:442-452

16. Prevoo ML, Van't Hof MA, Kuper HH, van Leeuwen MA, van de Putte LB, van Riel PL et al (1995) Modified disease activity scores that include twenty-eight-joint counts. Development and validation in a prospective longitudinal study of patients with rheumatoid arthritis. Arthritis Rheum 38:44-48

17. Leeb BF, Andel I, Sautner J, Bogdan M, Maktari A, Nothnagl T, Rintelen B (2005) Disease activity measurement of rheumatoid arthritis. Comparison of the SDAI and the DAS28 in daily routine. Arthritis Rheum 53(1):56-61

18. Aletaha D, Nell VPK, Stamm T, Uffmann M, Pflugbeil S, Machold K, Smolen JS (2005) Acute phase reactants add little to composite disease activity indices for rheumatoid arthritis: validation of a clinical activity score. Arthritis Res Ther 7:R796-R806

19. van der Heijde D, Dijkmans B, Geusens P, Sieper J, DeWoody K, Williamson P et al (2005) Efficacy and safety of infliximab in patients with ankylosing spondylitis: results of a randomized, placebo-controlled trial (ASSERT). Arthritis Rheum 52(2):582-591

20. Garrett S, Jenkinson T, Kennedy LG, Whitelock H, Gaisford P, Calin A (1994) A new approach to defining disease status in ankylosing spondylitis: the bath ankylosing spondylitis disease activity index. J Rheumatol 21(12):2286-2291 
21. Klareskog L, van der Heijde D, de Jager JP, Gough A, Kalden J, Malaise M, TEMPO (Trial of Etanercept and Methotrexate with Radiographic Patient Outcomes) study investigators et al (2004) Therapeutic effect of the combination of etanercept and methotrexate compared with each treatment alone in patients with rheumatoid arthritis: double-blind randomised controlled trial. Lancet 363(9410):675-681

22. St Clair EW, van der Heijde DM, Smolen JS, Maini RN, Bathon JM, Emery P et al (2004) Active-controlled study of patients receiving infliximab for the treatment of rheumatoid arthritis of early onset study group. Combination of infliximab and methotrexate therapy for early rheumatoid arthritis: a randomized, controlled trial. Arthritis Rheum 50(11):3432-3443

23. Sokka T, Pincus T (2003) Eligibility of patients in routine care for major clinical trials of anti-tumor necrosis factor alpha agents in rheumatoid arthritis. Arthritis Rheum 48(2):313-318

24. Zink A, Strangfeld A, Schneider M, Herzer P, Hierse F, Stoyanova-Scholz M, Wassenberg S, Kapelle A, Listing J (2006) Effectiveness of tumor necrosis factor inhibitors in rheumatoid arthritis in an observational cohort study: comparison of patients according to their eligibility for major randomized clinical trials. Arthritis Rheum 54(11):3399-3407

25. Pincus T, Sokka T, Chung CP, Cawkwell G (2006) Declines in number of tender and swollen joints in patients with rheumatoid arthritis seen in standard care in 1985 versus 2001: possible considerations for revision of inclusion criteria for clinical trials. Ann Rheum Dis 65(7):878-883 Epub 2005 Dec 8

26. Hynes RB, Sacket Dl, Gray JMA, Guyett GH (1996) Transferring evidence from research into practice. 1 . The role of clinical care research evidence in clinical decisions. Evid.-Based Med 1:196-197

27. www.Rheuma2000.at

28. Elliott MJ, Maini RN, Feldmann M, Kalden JR, Antoni C, Smolen JS, Leeb B, Breedveld FC, Macfarlane JD, Bijl H et al (1994) Randomised double-blind comparison of chimeric monoclonal antibody to tumour necrosis factor alpha (cA2) versus placebo in rheumatoid arthritis. Lancet 344(8930):1105-10

29. Baraliakos X, Listing J, Rudwaleit M, Brandt J, Sieper J, Braun J (2005) Radiographic progression in patients with ankylosing spondylitis after two years of treatment with the tumor necrosis factor-a antibody infliximab. Ann Rheum Dis 64:1462-1666

30. Keystone EC, Kavanaugh AF, Sharp JT, Tannenbaum H, Hua Y, Teoh LS et al (2004) Radiographic, clinical, and functional outcomes of treatment with adalimumab (a human anti-tumor necrosis factor monoclonal antibody) in patients with active rheumatoid arthritis receiving concomitant methotrexate therapy: a randomized, placebo-controlled, 52-week trial. Arthritis Rheum 50(5):1400-1401

31. Pincus T, Summey JA, Soraci SA Jr, Wallston KA, Hummon NP (1983) Assessment of patient satisfaction in activities of daily living using a modified Stanford Health Assessment Questionnaire. Arthritis Rheum 26:1346-1353

32. Wolfe F (2000) A reappraisal of HAQ disability in rheumatoid arthritis. Arthritis Rheum 43(12):2751-2761

33. Pincus T, Segurado OG (2006) Most visits of most patients with rheumatoid arthritis to most rheumatologists do not include a formal quantitative joint count. Ann Rheum Dis 65(6):820-822

34. Leeb BF, Haindl PM, Maktari A, Nothnagl T, Rintelen B (2008) Patient-centered rheumatoid arthritis disease activity assessment by a modified RADAI. J Rheumatol 35(7):1294-1299

35. Pincus T, Yazici Y, Bergman M, Maclean R, Harrington T (2007) A proposed continuous quality improvement approach to assessment and management of patients with rheumatoid arthritis without formal joint counts based on quantitative routine assessment of patient index data (RAPID) scores on a multidimensional health assessment questionnaire (MDHAQ). Best Pract Res Clin Rheumatol 21(4):789-804

36. Salvarani C, Cantini F, Olivieri I, Macchioni P, Padula A, Niccoli L et al (2003) Efficacy of infliximab in resistant psoriatic arthritis. Arthritis Rheum 49(4):541-545

37. Gérard S, le Goff B, Maugars Y, Berthelot JM (2008) Six-month response to anti-TNF drugs in axial spondylarthropathy according to the fulfillment or not of New-York criteria for ankylosing spondylitis or French recommendations for anti-TNF use. A "real life" retrospective study on 175 patients. Jt Bone Spine 75 (6):680-687

38. Zhang B, Lavalley M, Felson DT (2009) The sensitivity to change for lower disease activity is greater than for higher disease activity in rheumatoid arthritis trials. Ann Rheum Dis 68:1255-1259

39. Leeb BF, Sautner J, Leeb BA, Fassl C, Rintelen B (2006) Lack of agreement between patients' and physicians' perspectives of rheumatoid arthritis disease activity changes. Scand J Rheumatol 35(6):441-446

40. Pincus T, Yazici Y, Bergman MJ (2008) Quantitative rheumatology. Hotel-based medicine. J Rheumatol 35:1487-1489 